\title{
THE DISABLED FAMILY IN RURAL INDIA: EMPOWERMENT OF THE SOCIALLY-ABLED SELF
}

\author{
ADINA FAYE KARTEN \\ Goucher College, USA
}

\begin{abstract}
This ethnographic qualitative research through interviews of disabled people and their family members in rural Maharashtra, India, explores the inclusion of disabled members within village society. With limited access to healthcare, disability is seen as an unavoidable aspect of life. The aim of this research is to provide evidence that disabled people in rural areas are not usually isolated and abused or perceived as burdensome to their family members, contradicting generalized assumptions that often inform development literature. I suggest that generalized stigma of these disabilities is likely created during society's development from agrarian to industrial, in which disabled members' productivity levels do not increase with society's greater efficiency, thereby creating social fracturing due to perceived inability to participate economically. Stigma and poor adaptation to disability status are linked to inability to ascribe to socially acceptable roles. However, if a disabled person is able to marry and work to the maximum of their ability, they maintain a self-actualized identity. I term this identity the "socially-abled self," in which their selfhood is defined by their familial roles and their economic contributions to the household. Stigmatized disabilities are generally limited to leprosy, tuberculosis, HIV/AIDS and other severely socially limiting disabilities such as deaf-blindness and schizophrenia who have lives defined by a stigma triangle, in which inability to fulfil societal expectations of normalcy fears of contagion and ostracism feed each other cyclically. Therefore, inclusive development projects aimed at integrating disabled members should pay attention to existing familial support and focus beyond medical rehabilitation and even education, but extend to integrating stigmatized villagers economically, whether the stigma's source is gender, caste, or disability. By giving them an integral economic position in the society, the community learns to respect them by their trade, thereby allowing them to fully participate in community activities.

Keywords: rural development, India, stigma, inclusion, disability.
\end{abstract}

\section{INTRODUCTION}

Despite experts warning me of the familial isolation and abuse of disabled people, like myself, in the developing world, and particularly within rural areas, one my first experiences in rural India was a mother interrupting her disabled daughter's bath to meet me, insisting not only that I acknowledge her as part of the family, but that she meet me, an American woman with a cane.

And yet, stories about hiding, neglect, and even infanticide of disabled people in the developing world are presented as universal practice by authoritative sources such as the WHO as a "general and current problem" [1]. But when Benedicte Ingstad, an English anthropologist, informed the director of a Ministry of Health rehabilitation program in Botswana that she had come there to research how families cope with taking care of disabled family members, Ingstad was chided by the director who said, "You must know that in this country people hide their disabled family members in the lands, (isolated inside their homes with the suggestion of abuse)" [1]. However, Ingstad was not discouraged, and dubbed this worldwide assumption of isolation and disability in the developing world as "the myth of the hidden disabled" [1]. Ingstad's work postulates that abuses of the disabled in the developing world are unfortunate exceptions, just like the abuses in the West are assumed to be. 
Shaun Grech, an anthropologist from Malta, experienced similar deterrence when approaching the field in rural Guatemala [2]. However, he found that not only do families take care of their disabled members, they often go to far lengths and extreme poverty to support them, sometimes even nearing starvation themselves. For this reason, he coined the term "disabled families" rather than the before used "disabled households"; disability of one family member is an intrinsic aspect of the livelihood and wellbeing of the entire family.

Karangwa et al. built upon Grech and Ingstad's research by comparing the inclusion of disabled members in both urban and rural villages in Rwanda [3]. She came to the realization that poverty generally isn't the cause of exclusion of disabled family members as assumed, but rather, the poorest families with the least resources are more likely to integrate their disabled family members in family and community events. In fact, contrary to many development assumptions, families in urban areas are much more likely to isolate disabled family members, as they must commute to work [3]. Rural members generally live in small, single room homes, where isolation of disabled members is impossible due to the agrarian home-based nature of their lifestyle

Despite these studies that clearly show disabled members integrated into their social environment, older assumptions about the abuse of disabled people in lesser-developed contexts continue to influence development projects. Research regarding this assumption about the abandonment of disabled people in the developing world, particularly in rural areas, continues to be a common myth in the Global South and among development administrators alike. Authoritative sources such as the UN and the WHO warn about the mistreatment of disabled members of developing communities without much insight or research into their daily lives [4]. This assumption leads to post-colonial urban administrators assuming the worst about their communities, an assumption that is by no means unique to India.

Disability as a category is profoundly relational, determined by cultural conceptions of what the body should do and shaped by social conditions that exclude full participation in society [5]. Moreover, disabilities are negotiated differently given different contexts. For example, a condition like epilepsy may be interpreted as a divine gift, or an ancestral curse [6], [7]. Family members with disabilities may be hidden and silenced, integrated as laborers, or encouraged to migrate from villages to cities in search of education, work, or services [8], [9]. Those who do migrate are separated from their support network and are often less successful economically than they would be in rural areas, having to resort to begging, as observed in Jaipur and Delhi. Both disabled and abled bodied migrants tend to be less financially successful and retain lower quality of life than non-migrants, though migration is usually in one direction, as they are often too embarrassed to return to their villages. Migration is not only typically an unsuccessful path for village migrants, but also deprives villages of skilled members of their community that could help catalyze development within their own towns.

Anita Ghai [5], a polio survivor in Delhi, theorizes that the current disability models contain the disabled in a binary opposition, impeding liberation. Peters [10] asserts that to establish a positive self-identity, the disabled must identify their uniqueness in crossdisability culture rather than in binary opposition of able bodies. The discourse must be decentered from the dominant ethnocentric able-bodied discourse, establishing itself with an individual identity outside of the other [10].

According to Grech [11] "the colonial 'civilising' mission introduced racial 'Otherness' as the key ideological component for colonialism to function, rule and dominate." Creating the native as the Other was crucial for colonization to flourish. Quijano [12] relates that the idea of race did not exist pre-colonization and was instituted to mark the difference between the colonized and the colonizer. This was later expanded to include "supposed differential 
biological structures" that lay the groundwork for the modern eugenics movement [12]. Race and racism were more than instrumental, but constitutive of the colonial encounter and capitalist accumulation.

The Otherization of disability in the process goes beyond the marked biological differences. The violence of slave labor and subsequent corporal punishments left the native with visible lacerations and impairments, disabling the colonized and furthering the difference between them and the colonizer [11]. The violence and its visible manifestations both maintained and perpetuated the same biological and other categories of difference and racial superiority. Bodies became the medium in which these differences were permanently inscribed and displayed. The un-free body of the colonized slave became permanently scarred as a disabled body, where disability and colonialism fused together as "the deforming element, disfiguring all that has to do with beauty or morality ... the depository of maleficent powers" [13]. And in turn, these disabilities came together in mass, known as the "degenerate" and incorporating them among the Others, women, the working class, racial minorities, and disabled people [11].

By subjugating the colonized slave into a disabled body, the locus of freedom was consistently repositioned as nondisabled [2]. The punished body, now severely disabled, was removed from the physical labor. However, this was the same labor, which kept the slave virtuous; the Calvinism that created the West's capitalist economy values hard work above all else and sees one's ability to complete labor as a morally virtuous [14]. The nondisabled slave was never able to escape his blackness, but at least he was not broken for the purposes of his master. According to Grech [2], "This disabled Southern body is never disassociated from race, highlighting the biopolitical dialectic of regimentation."

The impaired slave was not seen as a helpless disabled body; rather it was a body imbued with resistance, malice, unruliness, and anxiety [11]. The incorrigibility of the disabled body was to be removed because he was not civilized and no longer a productive tool for the imperial project. The disabled body represented an unruly political force, which must be regulated because it defied and threatened the functioning and dealings of the empire through its very existence [11].

Colonization reframed and repositioned disability as a condition with signifiers and messages around the ideal colonized bodies, built around consciousness of the body, framing cultural normality of what the body can and cannot do [5]. This cultural signifier is what determines disability: what qualifies as a disability, the level of disability an impairment creates, and who faces ableism. This, in turn, sustains the depreciation of disabled bodies in the broader metanarrative of "compulsory able-bodiedness" [15]. Grech and Soldatic [16] emphasize, "Normativity therefore has strong historical roots and should be framed and analyzed in historically and geopolitically referential ways, traceable to what we may call a colonial normativity."

Trafficking of slaves was an early example of the creation of the "ideal" colonized body; slave traders would pay better prices for the stronger "able" prototype, as well as intellectual and other valued aspects including color, height, size, and facial features, thereby giving ablebodied normalcy objective economic value [16]. These bodily differences fueled the colonizer's fetish for aestheticizing difference. Disabled people were always worth less as productive slaves, and therefore slave traders went to great lengths to hide illnesses and impairments in hopes to get better market value.

Slave traders passing disabled slaves as able-bodied laid groundwork for the disabled ideal to pass as able-bodied at the cost of help and accommodation in modern society. Throughout history, disabled people were often then subjected and confined in this normalization process, 
by missionaries and Western medical professionals that imported charity and the European specialized institution [16].

The focus on the performative body in which is inscribed social and cultural meaning helps lay grounds for the corporeality of disability; laying the foundation for the medical model in which the primary interest is in bodily impairment rather than social experience or understanding [17]. This also may have contributed to the notion of the disabled body as a sinful, villainous figure [18].

These measures are merely an extension of the civilization mission and claim the main form of neo-colonization of the disabled body today. The disabled person is repositioned and defined "by their bodily impairment, in junctures of pathology/disease, spiritual depravity, charitable weakness/vulnerability, bio-psychosocial infection/contagion - bodies instigating the desire/impulse/will to first create anomalies and then to 'remedy' and cure them" [16]. At this point, missionary zeal aimed to cure the human spirit and body through medical and religious means, making the medical into a quasi-religious extension of God that would perforate the medical profession and garner extraordinary regimenting power over disabled bodies, especially in the Global North [19].

These measures, including but not limited to institutionalization and sterilization of the disabled people that continue to this day, isolate disabled people, cause extraordinary suffering, and created the process of destroying traditional forms of care within their communities as these bodies were examined in isolation, including of their own history [16]. In the context of colonial India, the missionaries "viewed disabled people as helpless, suffering humanity in need of the message of the Christ," people with "no past, no culture and no individuality...." [20]. Connecting disabled people to others in their image is vital to rehabilitation and self-esteem.

Disability has not only been constructed historically, it has also been locally engaged with for centuries within their own nations with various positive and negative judgments, far before the colonial invasion. Miles [21], for example, documents healing therapies and selforganized groups in many African countries spanning some 4000 years. There remains much need for engagement with disability in the Global South through close readings of historical texts, not only to learn about disability historically, but to reframe the Southern space and subject as one of agency, including humanity, and that it is within this space and agency that discourses need to be shaped and perhaps "solutions" sought [16]. Indeed, a global history of disability remains yet to be written. The absence of attention to colonial imperialism's relationship to Eurocentric disability studies is perhaps unsurprising, as the colonizer does not want to recollect colonialism which challenges his own civility. The colonial nation is rarely interested in owning up to crimes that they benefit from but feel they have nothing to do with. The colonized is perpetually left to trying to create not only interest in, but also legitimacy for, his/her own narrative.

Current inclusive development projects tend to emphasize the identity of the patient as an individual and therefore value individual rights, equality, and freedom of choice, contrasting with India and many other countries' more collectivist values [22]. Rehabilitation often means separating the disabled individual from their existing social framework and the support system of their family, thereby destroying the existing successes and starting from a new unstructured foundation. Nimbkar [23] explains:

In the West, the child is encouraged to "grow up," to "be a big boy," to do things for himself, and he is praised for taking such initiatives. The situation is quite the contrary in India. I have seen boys of five and six years of age sitting quietly while mother or servant or relative feed them. The situation is similar to the processes of bathing and dressing. This is a 
factor to be considered in the care of the handicapped child, in light of our [the practitioner's] desire to make him as independent and 'normal' as possible.

The unsuitability of imported rehabilitative technology goes far beyond the differing structures of individualistic based models versus collectivist ones. Miles disparages the inclusive development projects as irrelevant to rural Indian needs; there are few stairs in rural India as most of the population lives in single-floored houses. Additionally, Gokhale (1981) warns that rehabilitation of disabled members must be considered within the context of cultural society rather than purely physical needs. In the 1980s, an Indian village barber with limited mobility but with the ability to stand, was "rehabilitated" with a wheelchair from Bombay. Upon returning to his village, the barber found that the wheelchair left him unable to resume his profession as a barber: his status and caste within his rural community did not permit him to serve his clientele seated in a chair (Gokhale 1981).

While the community-based rehabilitation (CBR) model pioneered the effort to include the community and family members in their rehabilitation projects (Periquet 1984) and offered a functional, rather than clinical approach (Werner 1987), disability advocates critique the model as still far too individualistic and dependent on outside resources and interventions. Werner (1987) offers that the model assumes, "a considerably sophisticated level of coordination of health, vocational, educational, and social services in countries where disability issues are low priority" (Kalyanpur 1996).

Kalyanpur (1996) argues that depending on the severity of a person's disability, the disabled enjoy some amount of social integration and participation. Rather than preventing cultural mishaps such as Gokhale's (1981) example of the Indian barber being rehabilitated in a wheelchair that socially prevented him from serving clients, Kalyanpur (1996) argues that the CBR model still creates a dependence of the disabled on highly skilled specialists to create technology that often translates poorly to the village setting and is unreliably implemented. When the CBR model is implemented, it creates dependence on the practitioner. By that nature, families feel helpless without continued intervention (Kalyanpur 1996). The CBR model "has done little to recognize, respect, and build on the resources, skills, and strengths that already exist within local communities" (Kalyanpur 1996:256). Therefore, the poor implementation of the CBR model by village health workers may be due to the unsuitability of the model rather than stigma against disabled community members.

\section{METHODS}

In the following account, I attempt to give agency to the disabled people I interviewed to tell their own story, from their perspective, from a story that is disability led and informed. I conducted my qualitative research in the form of semi-structured interviews and participant observation, a research guideline that was previously approved by the Local Review Board in Delhi. These accounts were contextualized with the participant observation I had conducted throughout my travels in rural villages throughout Rajasthan and Uttar Pradesh in addition to Jamkhed's surrounding villages and contrasted with the experience of living in urban New Delhi and visits to Jaipur, Udaipur, and Lucknow.

CRHP is located in a small town called Jamkhed in Maharashtra, India, known for its weekly cattle market by villagers nearby. CRHP is a development center formed in the 1970s that chose Jamkhed because of how undeveloped the region was. Their philosophy is teaching villagers how to develop their communities themselves, using the resources they have in their community. CRHP also makes strategic efforts like placing wells in Dalit sections of town during droughts in order to mitigate the effects of the caste system. The region is very much agrarian and has little exposure to visitors other than those who work for the organization. 
I gathered informants from both Jamkhed itself and the villages surrounding. Many of the informants were connected to CRHP through employment or family member's employment, though care was also taken to survey the project villages (villages in which CRHP has affiliation) for other disabled members of the community that CRHP does not employ. Interviews were conducted with nine disabled informants with non-stigmatized disabilities, two with stigmatized disabilities, eight familial caregivers, and various informal conversations with the mobile health team, translators, and the two children of the founders of CRHP who now play the role of administrators of the project. In addition to the month I spent formally researching the disabled subjects and their families, I spent an extra month interning for the organization and learning their strategy in employing their mission.

Disabled informants were chosen based upon caste, religion, income and gender to get a representative sample of the community surrounding Jamkhed. In addition to those with arm and leg impairments, I had the opportunity to hear stories of many other community members, including those who overcame stigma of their community through the involvement of CRHP.

In order to determine whether age of disability onset is a factor in general acceptance from the disabled, their family members, and their community, I looked for informants who acquired their disabilities before and after the age of identity formation according to Stryker and Burke (2000). Rather than judge severity of impairment from an objective test made outside of the community, I allowed informants themselves to determine their standing and couched their stories only in their own perspective. Disabled informants were chosen according to their own definition of "having problem", the translated term for disability in the community. Because I aimed to study socialization and relation to the family in the context of chronic impairment, disability type was not considered important; rather, people had to identify themselves as a disabled subject, rather than a Western identity defined by the medical model or even impairment type.

The semi-structured interviews covered informant's life history, their relationship to their family and their community, their daily routine, conception of self-versus the conception of their disability, and their self-reported quality of life. If the informant spoke English, I used vernacular language whenever possible, allowing their lens to reflect their story, only editing for clarity. Thematic codes were created retroactively based upon their answers to reinforce the disabled-led, disabled-defined "Nothing about us, without us" nature of this paper.

\section{RESULTS AND DISCUSSION}

Regardless of caste or religion, in South Asia the care of the aged, the helpless, and the young is considered the duty of the family. The women of the family, usually the mother and sisters and other female relatives distribute the household chores to best accommodate their disabled children. Efforts are made to ensure that disabled individuals are accompanied at all times. While they are expected to do all possible jobs, there might be a relaxation in the amount of load carried, or the time taken to perform a particular task. Work distribution may entail the disabled sharing a greater load of the household chores while others pursue agricultural labor. A disabled woman often gets a lot of support in her natal home; however in her marital home she is expected to do all the household chores. In order to avoid this sudden removal of support, disabled women are often married into a joint household along with a sister either to the same man or a pair of brothers.

On the other hand, a man will never leave his joint family home, as his wife is expected to move in rather than he to move out, and he therefore enjoys the privileges of lighter chores throughout adulthood. Most of the disabled women continue to perform almost all the household chores, including fetching water from the well, cutting fodder, cooking, cleaning 
up, etc., all tasks that stretch their maximum bodily limit. One informant, a male polio survivor named Raju, described performing a similar amount of household work: usually tasks assigned to children.

Due to the strong interdependence of the familial unit, the informants I spoke to find their primary identity through their role in their family and their work. Nearly all my informants mentioned being good role models and providers for their children, when asked what they like about themselves. Often, they insisted on beginning their interviews by listing their family members' names, ages, and professions, before speaking about their selfhood, because of how intrinsic their family's role in their identity is. Each of the informants de-emphasized their limitations and focused on their family and technical abilities instead. With a socially accepted disability and with familial support and economic independence, my rural disabled informants develop a socially-abled selfhood, in which their disability is not a main factor in their quality of life or identity but rather just an aspect of their communal self and economic orientation.

The community seemed unbothered by the lesser productivity of their disabled members compared to able-bodied adults. One man explained, "In rural areas there are a lot of people like this with no medical facilities, so people adapt to this", in reference to disabilities from polio. Kailash, Raju's brother explained, "He is a burden, but at the same time, there is no alternative but to do his work". Kailash and Raju support each other as a familial unit and no resentment was exhibited.

A brother of another informant named Junaid laughed when I asked about Junaid's disability status, "He has two sons, and one of them is already earning money. So, he's not dependent". Junaid insists that life is not much different than before, laughing jovially. Before his stroke, Junaid managed his family tea stall. Now he no longer works but spends the majority of the day chatting with regulars at his family's stand. Despite his disability and resulting lack of financial productivity, Junaid remains self-actualized due to his sons' economic capacities, as they are sons are considered a financial extension of their parents and take care of the family in old age. In fact, the role of sons is so important, that people without sons of working age that have disabilities are less well adjusted to their disability status than those who's sons care for them economically. Village Health Workers in this community go so far as to say that the birth of a daughter instead of a son is a cause of postpartum depression.

With limited medical access, the disabled in rural developing communities are not expected to get better. Even if there is reliable medicine nearby, families often cannot afford to pay the doctor, or pay the financial burden of taking time off work. In India, the sick are rarely unaccompanied by a family member when receiving any type of medical care, so going to the doctor requires the loss of wages for at least two family members. Even though CRHP offers free medical care, the loss of wages during doctor's visits and hospitalizations are still an obstacle, especially if someone is in the Shudra caste and needs people at all times to maintain the farm and take care of the animals. Therefore, disability, even potentially curable disability, is exceedingly common due to lack of medical care. Though they may initially be reluctant, disabled individual usually adjust to their new limitations after a brief mourning period, especially if they have access to socially acceptable economic and physical support. Disabled people are allowed to participate in the community according to their abilities because all hands are needed for economic sustenance in rural areas. Rather than being forced to pass as able-bodied by keeping up with the same level of productivity, the disabled are allowed to develop a nuanced role of lesser productivity but remain contributors to the larger economy. In this way, they take the form of the termed socially-abled self, in which their disability is de-emphasized and their identity is defined by their economic and familial roles. 
In fact, people that seemed to have trouble adjusting to their disability status were those who were both unemployed and did not have access to a culturally normative method of adjusting to their limitations: for example, by lack of sons, as demonstrated by Kashabai, a female disabled elder in the Jamkhed community. People only feel burdensome if they are dependent on a person whose familial role does not typically support the relation in question.

Feroze, a 27-year-old man with an amputated leg, feels similarly burdensome. Because his sons are not old enough to work, he is dependent on his mother for financial support. Despite being economically stable, his dependence on his mother is not socially acceptable and, therefore, makes him feel "bored and broken". Having only been disabled for two years, Feroze has not had time to adjust to his new bodily limitations. The disabled early in their adjustment to their disability like Feroze tend to have a more difficult time adapting. Loss of capacity, compounded by dependence on a non-traditional household member, can lead to poor emotional adaption.

Given a positive economic stance, a spouse, and/or sons, disabled people have little variation in social standing than other villagers of their caste and gender.

The other side of villagers finding a socially acceptable route to take care of their disability is having a socially acceptable disability in the first place. The primary contrast between the prior informants and people with lower self-acceptance of their disabilities is the role that stigma plays. In Jamkhed, disabilities are stigmatized mostly due to perceived contagiousness, and stigmatized ailments are limited to leprosy, tuberculosis, HIV/AIDS, and schizophrenia. Though fear of contagion is the main source, the Otherization process is more complicated; fear of witchcraft, and socially unacceptable behavior are also related to the social conditions.

Stigma is more complex than fear of contagion or immorality. Some Hindus believe that disease is punishment for wrongdoing of you, yourself in a past life, or even that of a family member. The lack of education and awareness of villagers is particularly dangerous for those mentioned above. Some believe witchcraft cursed the disabled person with disease; a deadly assumption that can result in not only ostracism, but dangerous "quack" medicine and sometimes even murderous witch-hunts [24]. This is especially true in the case of schizophrenia, in which a person is especially unable to abide by prescribed social norms.

In a society where illness and disability are accepted as part of life, why is there such fear of contagion in these select illnesses? Many ailments have superstitious beliefs and quack treatments associated with them, without the diseased being ostracized from their communities. Contagious disease is common, with many children dying of preventable diarrheal diseases due to poor sanitation systems. After all, before polio was eradicated as recently as 2012, it was contagious in epidemic proportions, causing both death and disability. Still, Raju and other informants that survived polio were cared for by their families during their bout of polio and continue to be integrated into their community to this day. For this reason, I hypothesize that the selection of ostracized ailments is more complicated than mere postulates of contagion and witchcraft.

Perceived contagious and chronic ailments such as tuberculosis, HIV/AIDS, leprosy, and other severely socially limiting disabilities such as schizophrenia and deaf-blindness in Jamkhed district, Maharashtra, typically face stigmatization prior to intervention. In the selected stigmatized ailments people are placed in the center of a stigma triangle, (see Fig. 1.) in which the fear of contagion and variable ability feeds into perception of inability to maintain employment and contribute to the familial economy. The inability to reliably produce at a consistent level, along with the fear of contagion, keeps the ostracized out of the workplace, which feeds the stigma, as they are unable to maintain the social requirements of production and reproduction. 


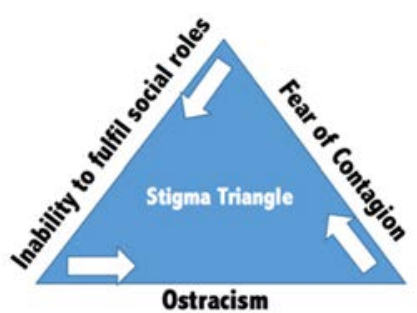

Figure 1: Stigma triangle.

Those with schizophrenia and other severe disabilities that outright prevent them from participating in the community's ascribed social expectations of normalcy are also assumed to be contagious, because the severity of their condition is misunderstood and confusing: why would the gods treat them so? Therefore, they are conceived to be cursed, either as omens for the rest of the community or as punishment for their previous lives. This is the time when abusive situations of neglect and isolation occur in both children and adults, but should not be generalized to extend to all disabilities or even considered a normalcy of the community. Instead, this is the exceptional result of different aspects of social deviance compounding together to form exceptional cases of social ostracism.

In Jamkhed district villages, the core of this ostracism is concentrated among those with severe mental illness and deaf-blindness. That is not to say all are abandoned by their families; some of these severely disabled are still members of their families, who either take care of them privately, or search for care and economic support in cities. This economic support often means utilizing disabled children as objects of pity for begging but is sometimes the only choice people have to take care of medical costs and food for the severely disabled. CRHP also currently rehabilitates several schizophrenics with a combination of medication and care at their demonstration farm in which they earn income and housing through employment. CRHP also educates a girl with deaf-blindness at their preschool even though she has passed the age in which she should be enrolled in elementary school and does not have the resources to truly thrive because of the severity of both her condition and social impairment.

There is great importance in analyzing these stories of the disabled, and especially those with stigmatized disease from an intersectional perspective. Had either of my stigmatized informants, Sakhubai, a Dalit with leprosy, or Ratna, a Shudra with HIV/AIDS, been from a higher caste or a better economic position, they would have received medical treatment long before their disease showed noticeable effects. If wealth were the case, Ratna and Sakhubai would have skipped the ostracism from their families and communities. Instead, due to their caste and economic positions, Ratna and Sakhubai are only fortunate exceptions, who did not die from their diseases due to intervention from a free hospital. Even more luckily for them, they were rehabilitated into jobs at CRHP, a development agency that created a stigma-free society on their campus and in their project villages.

Young or old, people's identities are defined by neither positive or negative associations with their disability; rather, they and their family's economic accomplishments, their children's marriages and existence of grandchildren are far more important in the formation of their identity. They are also less likely to feel connected to other disabled people with different impairments than themselves because they are not one complete oppressed social group. Rather, the bodily self is de-emphasized along with the identity of the individual. Instead, the individual defines himself by his interdependent social collective, a socially- 
abled self, focusing on the relations and the production that their familial connections depend on. Employment is important because of its role in taking care of the family, and the self is only important in that context. Even in stigmatized disabilities, the negative association comes from their lack of family and work, rather than their impairment. In rural India, there is no disabled self - there is only the disabled family, contingent on one another for survival, just as their able-bodied neighbors are interdependent on their own social support network.

\section{CONCLUSION}

Development is often equated with urban industrialization. It's an appealing idea: industrialization increases overall material wealth, restructures society, and creates important new schools of philosophy, but the social impact of industrialization is profound. For the first time since the Neolithic Revolution when humans formed civilizations and became stationary, people work outside of the local environment of their homes, therefore away from their disabled family members.

In Indian cities today, similar to many newly industrialized cities, children are sent to work in factories where they were exploited and ill-treated; women experienced substantial changes in their lifestyle as they take jobs in domestic service and the textile industries, leaving the agricultural workforce. The economic labor separates family members from the culture of their family homes. Because workers are exploited and expected to work long hours away from their home, disabled people became more isolated.

Stigmatization of the certain ostracized disabilities in the community are a result of a stigma triangle (see Fig. 1.): inability to reliably fulfil social roles feeds ostracism and the fear of contagion in a centrifugal way. Therefore, stigmatization primarily results from inadequacy to fulfil social norms. Development initiatives should focus on ameliorating not only medical contagiousness and educating community members, but also economic development. Education regarding lack of contagion alone cannot fully integrate a stigmatized member into society, because social integration requires more than the medical aspect of rehabilitation. Employment for the ostracized is necessary. Those with stigmatized positions, whether of low caste, gender, or disability, can best prove their worth by becoming vital resources for the rest of the community, employed in jobs that better the society, utilizing the "trickle-up" method of development [25]. This in turn lifts the entire community and gives sustainability to economic development. This form of development is dependent on the skills already intrinsic to the community, which benefits the rest of society, and therefore allows economic and social change, without creating a cultural upheaval dependent on outside funding.

In all productive revolutions, skill greatly determines quality of life. In urban industrialized society, it is harder for disabled people to prove their skill, as there are already more people than the economy can support, leaving able-bodied people unemployed as well. Therefore, disabled people have less social capital in the cities. This contradicts older beliefs regarding development that assumes greater development results in better social integration for the disabled. Instead, development must be carefully implemented to help integrate stigmatized members of the community without creating further social fracturing.

Much of the myth of the hidden disabled comes from the assumption that lesser education results in greater stigma. However, this is only true in the case of the stigmatized disabilities previously described, such as HIV/AIDS, schizophrenia, tuberculosis, deaf-blindness, and leprosy. Overall, people with disabilities in rural areas face less stigma than those in the postindustrial West or even urban centers within their developing countries, as they are not facing expectations of maximized productivity and competition with able-bodies for jobs in rural areas [14]. 
In agrarian societies, parents have as many children as they can to provide help around the farm. Disabled or not, everyone participates, maximizing their work to the limit of their ability, because it is necessary for survival. Usually, in the case of greater development, the population becomes more productive on both a societal and individual level. However, the productivity of the disabled individual doesn't generally increase due to limitations of his or her body, unless the disabled person is of a social class that provides them with the skills that come from education that guarantee employment. Therefore, the nuanced role of embodiment of the socially-abled self is hypothesized to be harder to achieve in urban centers: the model of the socially-abled self was developed to describe the social conditions in which allowed disabled members to fully participate in the community due to economic and social advancement that is particular to the economic realities of the rural environment. In this model, the disabled socially-abled self does not worry about his or her own future and is at peace with his or her own disability status, something that is achieved because of the unique interdependence required in rural developing areas.

In rural areas, people with non-stigmatized disabilities have a nuanced, socially-abled self, and are never expected to get medically cured. Therefore, they are never trapped in liminal space. The lack of binary opposition between disabled members of the rural community and their peers debunks the older assumption that community integration is dependent on increased development. For many disabled people, it is easier socially to live in rural areas because of the outpouring of community support. Generalized stigmatization of disability as a whole is caused by their perceived physical or mental inefficiency and therefore perceived inability to make income and is not intrinsic to a society until urbanization. Through urban industrialization, efficiency becomes a major desire in all employees, to make maximum output. In cities, there is no dearth of potential employees; as disabled people are assumed to be less efficient, their main source of economic viability comes through begging.

In regard to development, it cannot occur through force; passive urbanization works neither on socially or economically. Rather, the resources of the community should be utilized to create sustainable development. Agricultural industry should not be disregarded, and even bringing industrial agriculture to an area shouldn't be initiated unless there is a demonstrated need and request. In general, the principle of axiom of choice thoroughly determines when and how development should be occurring: communities generally know their own needs best.

\section{ACKNOWLEDGEMENTS}

First, I'd like to acknowledge my informants for sharing the piece of their lives they gave me. Thank you to my advisors, at SIT, Bhavnaji, Archnaji, Goutamji, Azimji, and Abidj; to my mentors at CRHP, Lexi Barab, Ravi and Dr. Shobha Arole, Jayesh and Ratna Kamble; and my professors, Carolyn Schwarz, Rory Turner, Eric Singer and Gina Shamshak. I couldn't have done this without any of you. And most importantly, thank you so much to Adam, Meg and Emily for giving me the physical space to conceptualize this article - and my parents for endlessly encouraging me.

\section{REFERENCES}

[1] Ingstad, B., The myth of disability in developing nations. The Lancet, 354(9180), pp. 757-758, 1999. DOI: 10.1016/s0140-6736(99)06049-3.

[2] Grech, S., Disability and Poverty in the Global South: Renegotiating Development in Guatemala, Palgrave Macmillan: Basingstoke, GB, 2015.

[3] Karangwa, E., Miles, S. \& Lewis, I., Community-level responses to disability and education in Rwanda. International Journal of Disability, Development \& Education, 57(3), pp. 267-278, 2010. DOI: 10.1080/1034912x.2010.501183. 
[4] Khasnabis, C. \& Motsch, K.H., Towards Community Based Inclusive Development, WHO: Geneva, 2010.

[5] Ghai, A., Rethinking Disability in India, Routledge: India, 2015.

[6] Biehl, J.G., Vita: Life in a Zone of Social Abandonment, University of California Press: Berkeley, 2005.

[7] Ingstad, B. \& Whyte, S.R., Disability and Culture, University of California Press, 1995.

[8] Eide, A.H. \& Ingstad, B., Disability and poverty: A global challenge 2011. Online. http://public.eblib.com/choice/publicfullrecord.aspx?p=726872.

[9] Phillips, N., Migration in the Global Political Economy, Lynne Rienner: Boulder, CO, 2011.

[10] Peters, S., Is there a disability culture? A syncretisation of three possible world views. Disability and Society, 15, pp. 583-601, 2000.

[11] Grech, S., Decolonising Eurocentric disability studies: Why colonialism matters in the disability and global South debate. Social Identities, 21, pp. 6-21, 2015. DOI: 10.1080/13504630.2014.995347.

[12] Quijano, A., Coloniality of Power, Eurocentrism, and Latin America. 1st ed., Views from the South: Nepantla, 2000.

[13] Fanon, F., The Wretched Earth, Penguin: London, 1963.

[14] Weber, M., The Protestant Ethic and the Spirit of Capitalism, Scribner: New York, 1998.

[15] McRuer, R., Disability nationalism in crip times. Journal of Literary and Cultural Disability Studies, 4, pp. 163-178, 2010.

[16] Grech, S. \& Soldatic, K., Disability and colonialism: (dis)encounters and anxious intersectionalities. Social Identities, 21(1), pp. 1-5, 2015. DOI: 10.1080/ 13504630.2014.995394.

[17] Siebers, T., Disability in Theory: From Social Constructionism to the New Realism of the Body. Disability Studies Reader, Routledge, Taylor and Francis Group: New York, pp. 173-84, 2006.

[18] Davis, L., Enforcing Normalcy: Disability, Deafness and the Body, Verso: London, 1995.

[19] Oliver, M., The Politics of Disablement, Macmillan: Basingstoke, 1990.

[20] Dalal, A.K., Enforcing normalcy: Disability, deafness and the body. Zeitschrift Behinderung Und Dritte Welt, 2, pp. 65-69, 2003.

[21] Miles, C., Ethnic and linguistic minority children with special needs: a critical review of educational language and culture. Behinderte Menschen am Rande der Gesellschaften. ALBRECHT, F. \& WEIGT, G., Frankfurt: Verlag fur Interkulturelle Kommu- nikation, 1993.

[22] Kalyanpur, M., The influence of Western Special Education on Community-based services in India. Disability and Society, 11(2), pp. 249-270, 1996. DOI: 10.1080/09687599650023263.

[23] Nimbkar, K., Eighteen years after. Journal of Rehabilitation in Asia, 14, pp. 10-13, 1973.

[24] Shaffer, R., Modern witch hunting and superstitious murder in India. Skeptical Inquirer, 38, 2014.

[25] Smarandache, F. \& Christianto, V., The Trickle Up Effect: A Collection of Economic and Scientific Papers, LAP LAMBERT Academic Publishing: Germany, 2013. 